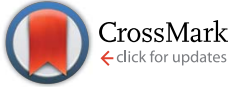

Cite this: RSC Adv., 2017, 7, 7163

Received 24th November 2016 Accepted 29th December 2016

DOI: 10.1039/c6ra27302e

www.rsc.org/advances

\title{
Design and synthesis of dual probes for detection of metal ions by LALDI MS and fluorescence: application in $\mathrm{Zn}(\mathrm{II})$ imaging in cells $\uparrow$
}

\author{
Arundhoti Mandal, ${ }^{a}$ Asim Maity, ${ }^{a}$ Swarnendu Bag, ${ }^{\text {b }}$ Prabuddha Bhattacharya, ${ }^{a}$ \\ Amit K. Das ${ }^{c}$ and Amit Basak ${ }^{* a}$
}

\begin{abstract}
A Label-Assisted Laser Desorption/Ionization (LALDI) technique has recently been applied to the detection of metal ions through a time of flight (TOF) mass spectrometric measurement. In this paper, we report the synthesis of two terpyridine based ligands L1 and L2 containing a pyrene moiety. The presence of the latter helped the ligand metal complex to desorb from the surface and ionize upon laser irradiation and finally show up in the TOF MS. Both ligands were able to detect $\mathrm{Zn}^{2+}, \mathrm{Ni}^{2+}$ and $\mathrm{CO}^{2+}$ ions while $\mathrm{Cu}^{2+}, \mathrm{Fe}^{2+}$ and $\mathrm{Mg}^{2+}$ remained LDI silent. Complexation with the ligands also caused a red fluorescence only with $\mathrm{Zn}^{2+}$ ions that allowed $\mathrm{Zn}^{2+}$ imaging in cells. Thus the pyrene moiety acted as a dual probe for metal ion detection exploiting both LALDI MS and fluorescence techniques.
\end{abstract}

\section{Introduction}

Metal ions play a crucial role in normal cellular function. ${ }^{\mathbf{1}}$ In biological systems, they can function in a number of different ways. They act as cofactors for many critical enzymatic reactions. $^{2}$ Some metals operate as structural elements ${ }^{3}$ and maintain charge and osmotic balance. ${ }^{4}$ Transition metal ions such as zinc(II), function as structural elements in superoxide dismutase $^{5}$ and in zinc finger proteins. ${ }^{6}$ There are also a number of reports on activation of chemical reactivity of small molecules upon metal ion chelation. ${ }^{7}$ For example, acyclic enediynes with terminal ligands undergo Bergman cyclization $^{8}$ at a lower temperature for the metal complexed system as compared to the uncomplexed one. Interestingly, presence of metal ions in excess or less in biological systems can have adverse effects. Every essential element follows a dose-response curve. At very low dosages, the organism struggles to survive, whereas in deficiency regions, the organism exists with sub-optimal function. Beyond the concentration plateau in the optimum dosage region, higher dosages cause toxic effects in the organism, eventually becoming lethal. ${ }^{9}$ Thus detection of metal ions that are

\footnotetext{
${ }^{a}$ Department of Chemistry, Indian Institute of Technology, Kharagpur 721302, India. E-mail:absk@chem.iitkgp.ernet.in

${ }^{b}$ Centre for Healthcare Science and Technology, Indian Institute of Engineering Science and Technology, Shibpur-711103, India

${ }^{c}$ Department of Biotechnology, Indian Institute of Technology, Kharagpur 721302, India
}

† Electronic supplementary information (ESI) available. See DOI: 10.1039/c6ra27302e playing critical roles in living systems, even at low concentrations, is of utmost importance for assessing health risk and environmental monitoring. The usual detection procedure includes traditional techniques like UV-VIS spectroscopy, ${ }^{\mathbf{1 0}}$ fluorescence spectroscopy, ${ }^{\mathbf{1 1}}$ Liquid Chromatography-Mass Spectrometry (LC-MS), ${ }^{\mathbf{1 2}}$ Atomic Absorption Spectroscopy (AAS), ${ }^{13}$ Inductively Coupled Plasma Atomic Emission Spectrometry (ICP/AES), ${ }^{\mathbf{1 4}}$ Inductively Coupled Plasma Mass Spectrometry (ICP/MS), ${ }^{15}$ Neutron Activation Analysis (NAA), ${ }^{\mathbf{1 6}}$ X-ray fluorescence (XRF), ${ }^{17}$ Ion Chromatography (IC) and High Performance Liquid Chromatography (HPLC), ${ }^{\mathbf{1 8}}$ surface plasmon resonance based optical sensors ${ }^{\mathbf{1 9}}$ and microfluidics based sensors. ${ }^{20}$ However, these methods have their own limitations like interference from other analytes. Even electrospray mass spectrometry (ESI MS) ${ }^{21}$ may be difficult for mixture of analytes as all the constituents will show up in the spectrum and make the analysis difficult. A method which can detect specific metal ions in biological or environmental samples will be extremely useful and the LALDI MS technique coupled with fluorescence can offers a viable solution.

Kozmin et al. ${ }^{22}$ used an LALDI MS technique for new reaction-discovery. Their strategy was based on labeling one of the reactants with a polyaromatic chemical tag (pyrene), which selectively underwent a photoionization/desorption process upon laser irradiation, without the assistance of an external matrix, and enabled rapid mass spectrometric detection of products originating from such labeled reactants in complex reaction mixtures without the need of any chromatographic separation. An example along with the principle behind their work is shown in Fig. 1. 

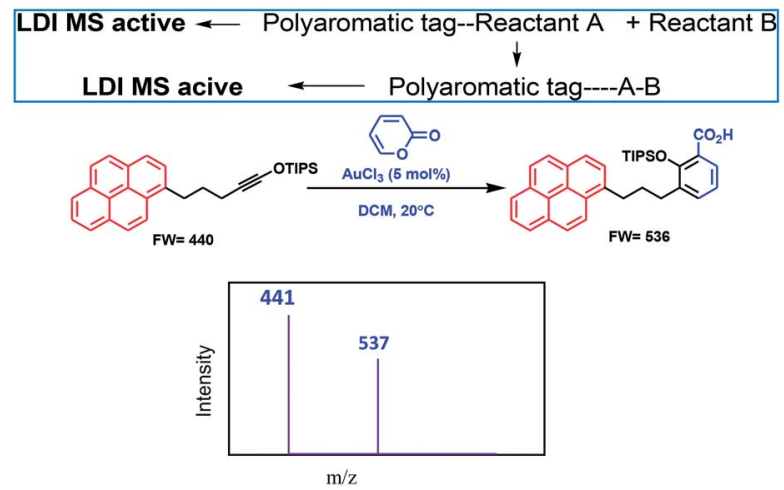

Fig. 1 Kozmin's work on reaction discovery

In recent years, our group has demonstrated the use of LALDI MS technique involving an oxine carboxylic acid-pyrene conjugate ligand for selective detection of metal ions like $\mathrm{Zn}^{2+} .^{23}$ However, although the detection was easily discernible, the quality of the spectra was less than satisfactory. This is because of low sensitivity and low absorption of the ligand at laser wavelength of $337 \mathrm{~nm}$ as well as appearance of extra peaks originating from the ligand. With the aim of improving the spectra particularly at the low level of detection and removal of extraneous peaks, we have designed the terpyridine based ligands $\mathbf{L 1}$ and $\mathbf{L 2}$ (Fig. 2) attached with a pyrene moiety through ester linkage or through conjugation. Terpyridine is a tridentate ligand that binds metals at three meridional sites and it forms complexes with transition metal ions. The ligand has been well exploited for complexation with various metal ions. Recently, Ghosh et al. ${ }^{24}$ have reported in an interesting paper the design and synthesis of an alkynyl terpyridine which has been shown to form octahedral complexes with metal ions like $\mathrm{Fe}^{2+}, \mathrm{Zn}^{2+}, \mathrm{Cd}^{2+}$, $\mathrm{Ru}^{2+}$ and $\mathrm{Pb}^{2+}$. Another recent work has been reported by Patra et $a{ }^{25}$ on terpyridine based sensor for detection of $\mathrm{Cd}^{2+}$. However, to our knowledge, there is no report of any pyrene based terpyridine ligand which has been used to serve the dual purpose of detection of metal ions by both LALDI MS as well as by fluorescence sensing. Pyrene moiety is known for its ability to act as an excellent LDI tag, due to its chemical inertness, ability to form radical cations and most importantly, very high molar extinction coefficient in the range 335-360 nm which allowed it to absorb laser radiation and subsequent desorption-cumionization. The pyrene-terpyridine conjugate should form chelate complex with analyte metal ions and the entire complex upon laser irradiation is expected to undergo desorption-cumionization and should be detectable by LDI-MS. The working principle is shown in the Fig. 3. In addition, the pyrene moiety
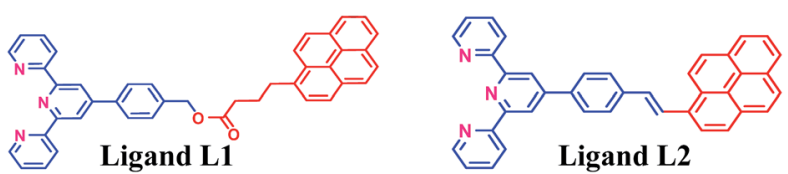

Fig. 2 Target polyaromatic ligands for LALDI based metal ion detection.

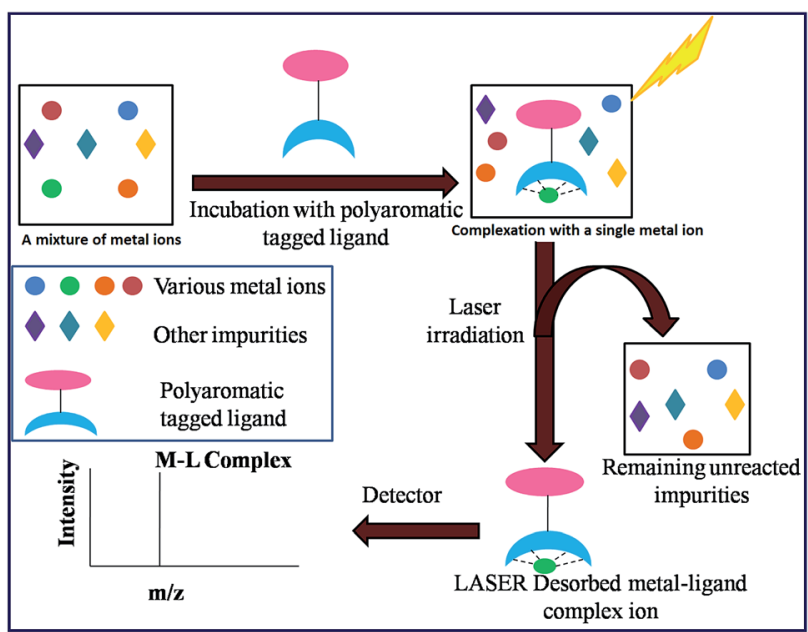

Fig. 3 Schematic diagram of working principle of LALDI-MS technique.

was also expected to serve as the fluorophore changing its emission spectra upon complexation. In this paper, we describe the synthesis of ligands $\mathbf{L} 1$ and $\mathbf{L} 2$ and report their ability to detect metal ions by using a combination of LALDI MS and fluorescence.

\section{Results and discussion}

Both the ligands were synthesized starting from a common intermediate, namely 4'-(4-bromomethylphenyl)terpyridine 2 (Fig. 4). For this, the tolyl terpyridine 1 was first synthesized following the literature procedure reported by Zecher and Kröhnke. ${ }^{26}$ This synthetic protocol involves condensation reaction between 2-acetyl pyridine and 4-methylbenzaldehyde in presence of ammonia and $\mathrm{NaOH}$ to yield intermediate 1. Allylic bromination was performed using NBS and AIBN on 1 to obtain

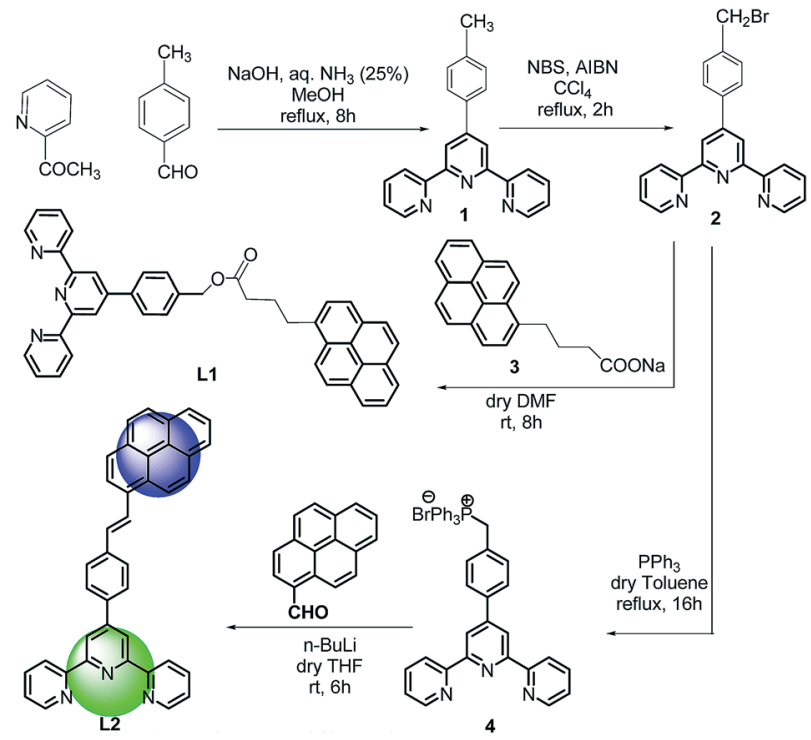

Fig. 4 Synthetic pathway of ligands L1 and L2. 


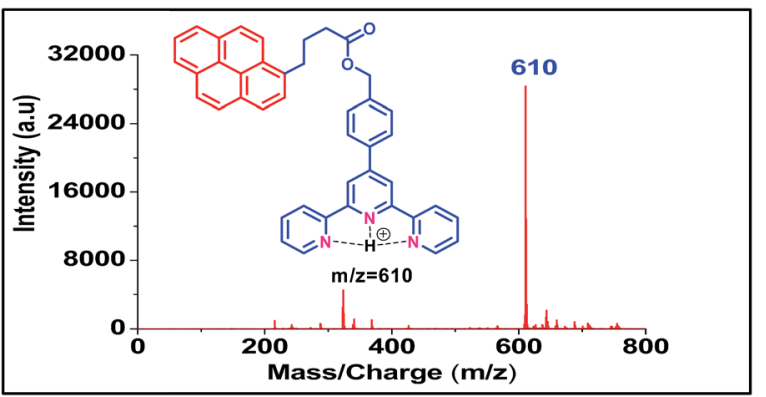

Fig. 5 LALDI mass spectrum of ligand L1.

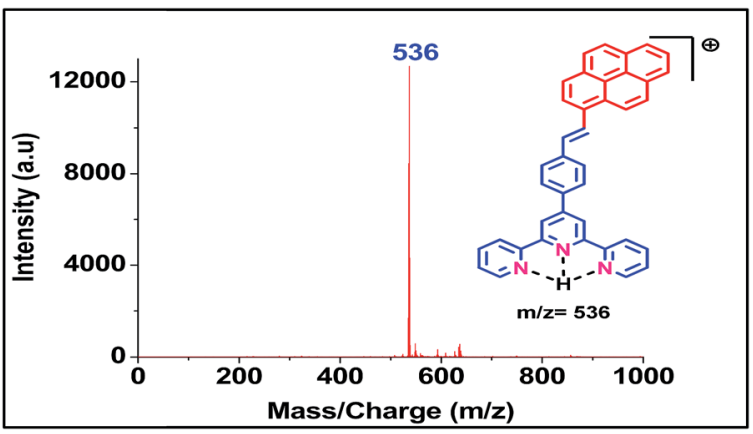

Fig. 6 LALDI mass spectrum of ligand L2.

compound 2. The desired ligand $\mathbf{L 1}$ was formed when $\mathbf{2}$ was reacted with sodium salt of pyrene butyric acid $\mathbf{3}$. The ligand $\mathbf{L 2}$ was synthesized via Wittig reaction between the Wittig salt 4 and pyrene aldehyde in presence of $n$-BuLi. The structures of $\mathbf{L 1}$ and $\mathbf{L} 2$ have also been confirmed by ${ }^{1} \mathrm{H},{ }^{13} \mathrm{C}$ NMR (included in ESI†).

With the ligands in hand, we first checked whether these are LDI active. For this, an aliquot of $1 \mu \mathrm{L}$ of the prepared ligand solution of $1 \mu \mathrm{M}$ in chloroform was spotted in the LDI plate and the mass spectrum (TOF-MS) was recorded. Due to high molar extinction coefficient of pyrene, ligand $\mathbf{L 1}$ showed a strong $[\mathrm{MH}]^{+}$peak at $m / z 610$ (Fig. 5) while ligand $\mathbf{L} 2$ showed the peak at $\mathrm{m} / z 536$ (Fig. 6). Expectedly, because of greater conjugation, the ligand $\mathbf{L} 2$ absorbs the laser to a greater extent and hence the corresponding LALDI spectrum of ligand $\mathbf{L 2}$ appeared to be clearer than ligand $\mathbf{L} 1$.

For screening the metal ion complexation, the concentration of probe ( $\mathbf{L} 1$ or $\mathbf{L} 2)$ was maintained at $0.1 \mu \mathrm{M}$ and that of metal

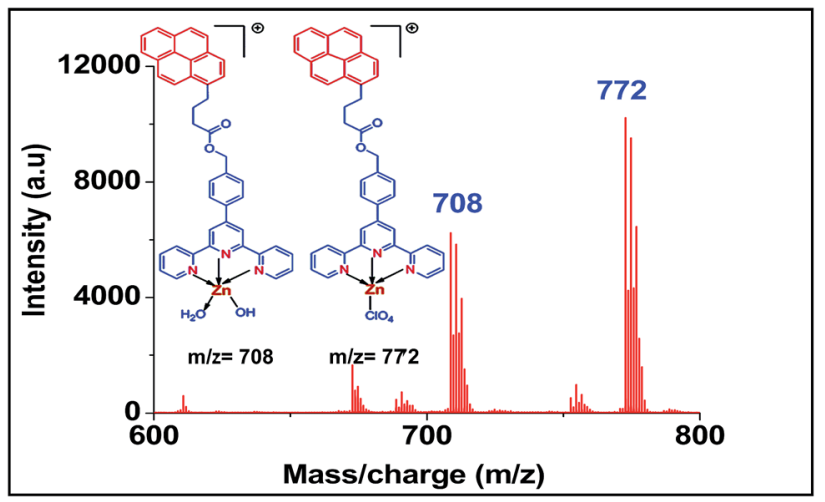

Fig. 7 LALDI mass spectrum of ligand $\mathrm{L} 1+\mathrm{Zn}\left(\mathrm{ClO}_{4}\right)_{2}$.

perchlorate salts at $1 \mu \mathrm{M}$ in acetonitrile. The reaction mixtures were incubated for $2 \mathrm{~h}$ at $40{ }^{\circ} \mathrm{C}$. An aliquot of $1 \mu \mathrm{L}$ from the reaction mixture were taken from each reaction mixture and analyzed (TOF-MS) in positive ion mode. The captured complexes of $\mathrm{Zn}^{2+}, \mathrm{Co}^{2+}, \mathrm{Ni}^{2+}$ were LDI active with typical isotopic distributions ${ }^{27}$ while $\mathrm{Fe}^{2+}, \mathrm{Cu}^{2+}$ remained LDI silent. The summarized results of the screening process are given below in Table 1. The spectrum for $\mathrm{Zn}^{2+}$ with $\mathbf{L} 1$ and $\mathbf{L 2}$ are shown in Fig. 7 and 8 respectively.

Regarding sensitivity of detection for $\mathrm{Zn}^{2+}$ using the present protocol, we could determine $\mathrm{Zn}^{2+}$ at an impressive level of $0.025 \mu \mathrm{M}$ (Fig. 9). The isotopic distribution also followed the theoretically predicted one (Fig. 10).

The LALDI mass spectrum of ligand $\mathbf{L} 2$ and $\mathrm{Co}\left(\mathrm{ClO}_{4}\right)_{2}$ was compared with the spectra obtained via conventional MALDI technique (Fig. 11). It clearly showed the advantage of LALDI over MALDI for small molecule detection. ${ }^{28}$

Moreover our synthesized probe can detect metal ion in presence of other organic impurities, ubiquitous in biological fluids like glucose, amino acid, $\alpha$-ketoglutaric acid and tartaric acid, which cannot be accomplished by any other LDI techniques (Fig. 12). Even it can detect the presence of all three metal ions like $\mathrm{Co}^{2+}, \mathrm{Zn}^{2+}$ and $\mathrm{Ni}^{2+}$ in a mixture (Fig. 13).

We have also recorded the fluorescence and UV-spectral changes upon complexation (Fig. 14 and 15). The UV and fluorescence experiments were carried out in acetonitrile medium at $10^{-5} \mathrm{M}$ concentration of ligand solution upon addition of incremental amount of metal perchlorate (in order of $200 \mu \mathrm{M}$ ). The UV-VIS spectrum of the ligand L1 exhibits maxima at $242 \mathrm{~nm}$ and $275 \mathrm{~nm}$. For $\mathrm{Zn}^{2+}, \mathrm{Ni}^{2+}$ and $\mathrm{Co}^{2+}$, upon gradual increase of

Table 1 Metal ion screening results with ligand L1 and L2

\begin{tabular}{lll}
\hline $\begin{array}{l}\text { Metal } \\
\text { ions }\end{array}$ & $\begin{array}{l}\text { Obtained peak of metal complexes } \\
\text { of ligand } \mathbf{L 1}(\mathrm{m} / \mathrm{z})\end{array}$ & $\begin{array}{l}\text { Obtained peak of metal complexes } \\
\text { ligand } \mathbf{L 2}(\mathrm{m} / \mathrm{z})\end{array}$ \\
\hline $\mathrm{Zn}^{2+}$ & 708,772 & 634 \\
$\mathrm{Ni}^{2+}$ & $667,684,702,766$ & $593,610,628,692$ \\
$\mathrm{Co}^{2+}$ & $668,685,703$ & 594,611 \\
$\mathrm{Fe}^{2+}$ & No significant peak & No significant peak \\
$\mathrm{Cu}^{2+}$ & No significant peak & No significant peak \\
$\mathrm{Mg}^{2+}$ & No significant peak & No significant peak
\end{tabular}




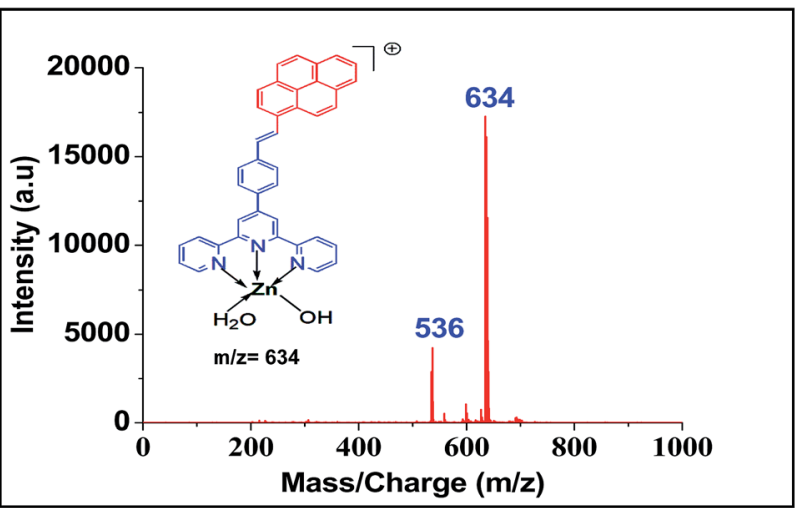

Fig. 8 LALDI mass spectrum of ligand $\mathrm{L} 2+\mathrm{Zn}\left(\mathrm{ClO}_{4}\right)_{2}$.

metal ion concentration, a new peak (284 nm for $\mathrm{Co}^{2+}$ and $285 \mathrm{~nm}$ for $\mathrm{Zn}^{2+}$ and $\mathrm{Ni}^{2+}$ ) was observed. No change was observed for $\mathrm{Fe}^{2+}, \mathrm{Cu}^{2+}, \mathrm{Mg}^{2+}$. Ligand $\mathbf{L} 2$ exhibited maxima at $384 \mathrm{~nm}$. For $\mathrm{Zn}^{2+}, \mathrm{Ni}^{2+}$ and $\mathrm{Co}^{2+}$ shift of ligand peak was observed i.e., $384 \mathrm{~nm}$ to $407 \mathrm{~nm}$ for $\mathrm{Zn}^{2+}$, to $403 \mathrm{~nm}$ for $\mathrm{Co}^{2+}$ and to $405 \mathrm{~nm}$ for $\mathrm{Ni}^{2+}$. No change was observed for $\mathrm{Fe}^{2+}, \mathrm{Cu}^{2+}, \mathrm{Mg}^{2+}$. This also indicates the greater chelating ability of terpyridine moiety towards $\mathrm{Zn}^{2+}, \mathrm{Ni}^{2+}$ and $\mathrm{Co}^{2+}$.

Fluorescence data for ligand $\mathbf{L} 2$ were recorded at excitation wavelength of $360 \mathrm{~nm}$. The free ligand showed emission maxima at $487 \mathrm{~nm}$. Upon gradual increase of metal ion concentration, quenching of fluorescence was observed for all metal ions. Many transition metals are known to be fluorescence quenchers, and they can quench fluorescence through energy transfer or electron transfer mechanisms. ${ }^{29}$ The phenomenon of quenching in case of $\mathrm{Zn}^{2+}, \mathrm{Ni}^{2+}$ and $\mathrm{Co}^{2+}$ was very high compared to $\mathrm{Fe}^{2+}, \mathrm{Mg}^{2+}, \mathrm{Cu}^{2+}$. The greater extent of quenching in case of $\mathrm{Zn}^{2+}, \mathrm{Ni}^{2+}$ and $\mathrm{Co}^{2+}$ suggested formation of complexes causing easier energy transfer. This is also supported by LALDI-MS and UV-VIS studies. In case of $\mathrm{Zn}^{2+}$, apart from quenching of fluorescence, a new peak was observed at $620 \mathrm{~nm}$ with increasing $\mathrm{Zn}^{2+}$ concentration (Fig. 15b and c), it also showed a vivid colour change from yellow to red under UV lamp (Fig. 16). The new peak may be due to ligand to metal ion intramolecular charge transfer (ICT). ${ }^{30}$ The synthesized ligand

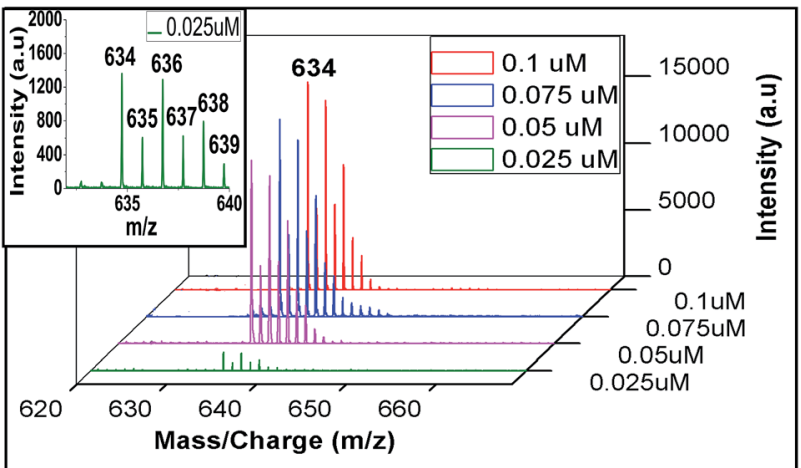

Fig. 9 Sensitivity detection of zinc ion by LALDI-MS using ligand L2, blown up spectra for $0.025 \mu \mathrm{M}$ concentration is shown in the inset.

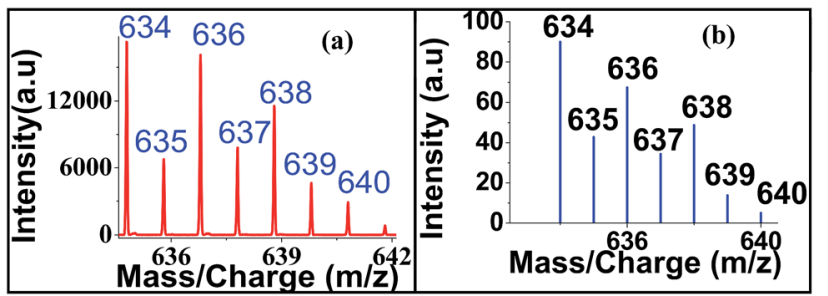

Fig. 10 Isotopic distribution of zinc-ligand L2 complex in LALDI mass spectra (a) experimentally (b) calculated obtained.

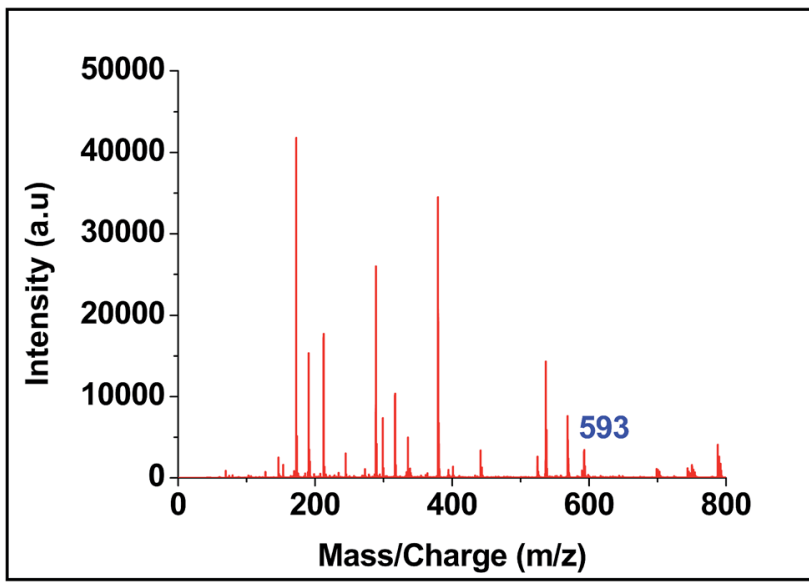

Fig. 11 MALDI mass spectrum of ligand $\mathrm{L} 2$ and $\mathrm{Co}\left(\mathrm{ClO}_{4}\right)_{2}$ in presence of $\alpha$-CHCA matrix.

L1 had very low fluorescent power, thus the experiment was carried out using a greater slit width of the fluorimeter. The fluorescence spectrum (Fig. 15a) of $\mathbf{L 1}$ was recorded at an excitation wavelength of $280 \mathrm{~nm}$ and it showed emission maxima at $378 \mathrm{~nm}$. Upon gradual addition of $\mathrm{Zn}^{2+}$ concentration, the nature of the curve completely changed indicating strong complexation. However, unlike L2, no new band in the visible region was observed. Small changes were also noticed for $\mathrm{Ni}^{2+}$ and $\mathrm{Co}^{2+}$, but no change was observed for $\mathrm{Fe}^{2+}, \mathrm{Mg}^{2+}, \mathrm{Cu}^{2+}$.

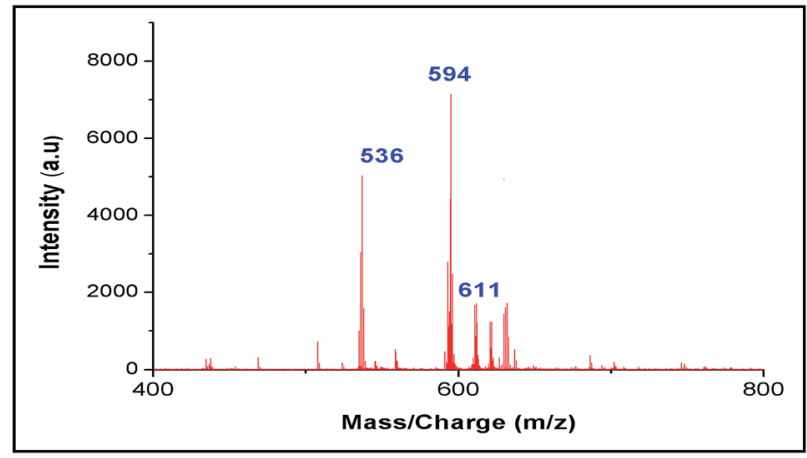

Fig. 12 LALDI mass spectrum of ligand $\mathrm{L} 2$ and $\mathrm{Co}\left(\mathrm{ClO}_{4}\right)_{2}$ in presence of other organic impurities like amino acids, $\alpha$-ketoglutaric acid, tartaric acid and glucose. 


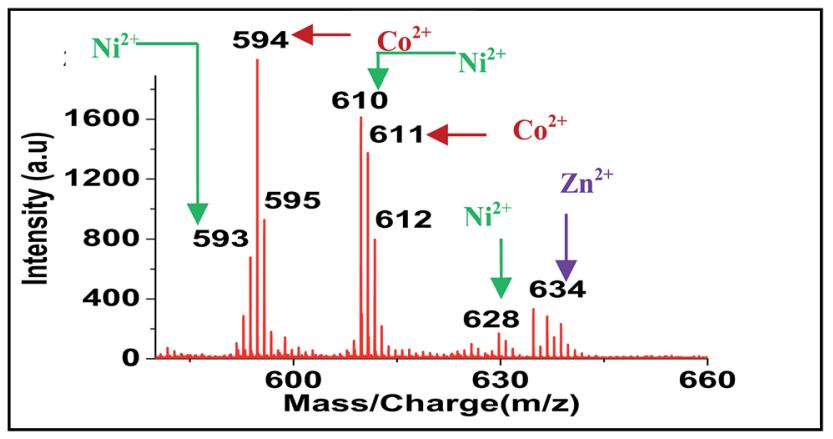

Fig. 13 LALDI mass spectrum of ligand $\mathrm{L} 2+\mathrm{Zn}\left(\mathrm{ClO}_{4}\right)_{2}+\mathrm{Co}\left(\mathrm{ClO}_{4}\right)_{2}+$ $\mathrm{Ni}\left(\mathrm{ClO}_{4}\right)_{2}$.

Encouraged by the outcome of fluorescence study we proceeded to the in vitro cell imagine for the staining of the zinc ion by the ligand $\mathbf{L} 2$. In this experiment we targeted HaCaT cell line for imaging studies. HaCaT is a spontaneously transformed aneuploid immortal keratinocyte cell line from adult human skin, widely used in scientific research. ${ }^{31}$

Considering the merits required for cell-imaging study, our object was to locate zinc ion in living cell by employing the higher fluorescent property of the ligand $\mathbf{L} 2$ and its greater affinity for zinc ion at biologically relevant environment.

As predicted beforehand, the ligand $\mathbf{L} 2$ can selectively sense zinc ions in cell. The control cells and the cells only treated with $\mathrm{Zn}\left(\mathrm{ClO}_{4}\right)_{2}$ showed no red (Fig. 17A and B) but blue fluorescence was observed due to staining of the nucleus by DAPI. The cells treated with only ligand $\mathbf{L} 2$ showing the red fluorescence having less intensity (Fig. 17C) but the cells treated with both zinc salt

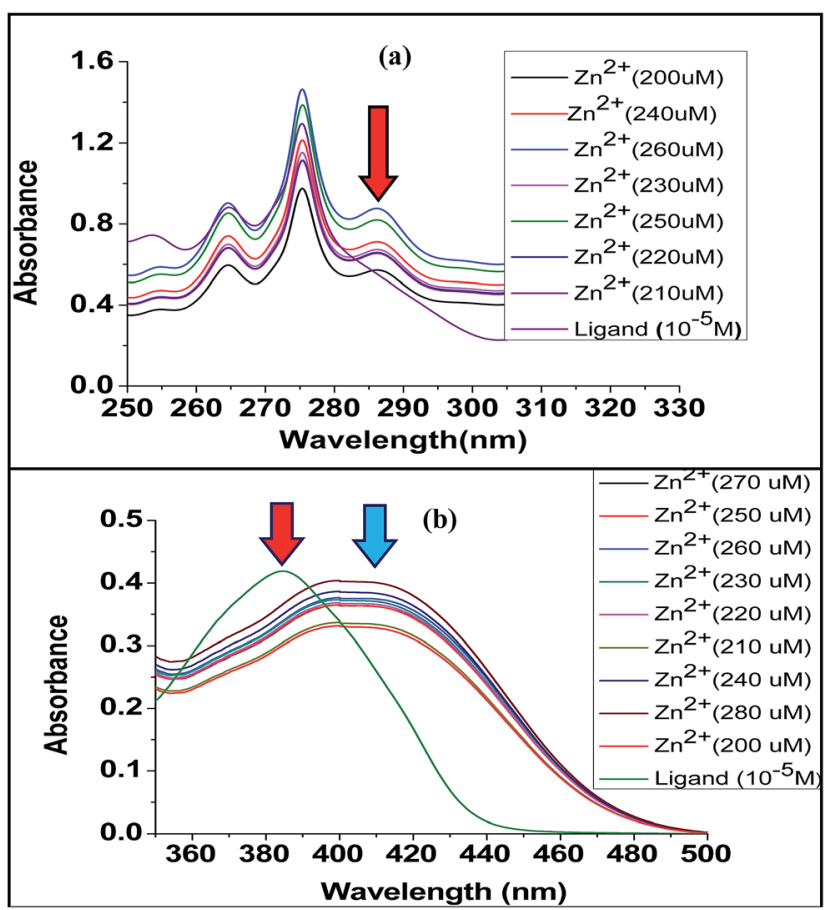

Fig. 14 Comparative UV-VIS titration curve: (a) ligand L1 and (b) ligand $\mathrm{L} 2$, each with increasing concentration with $\mathrm{Zn}\left(\mathrm{ClO}_{4}\right)_{2}$.
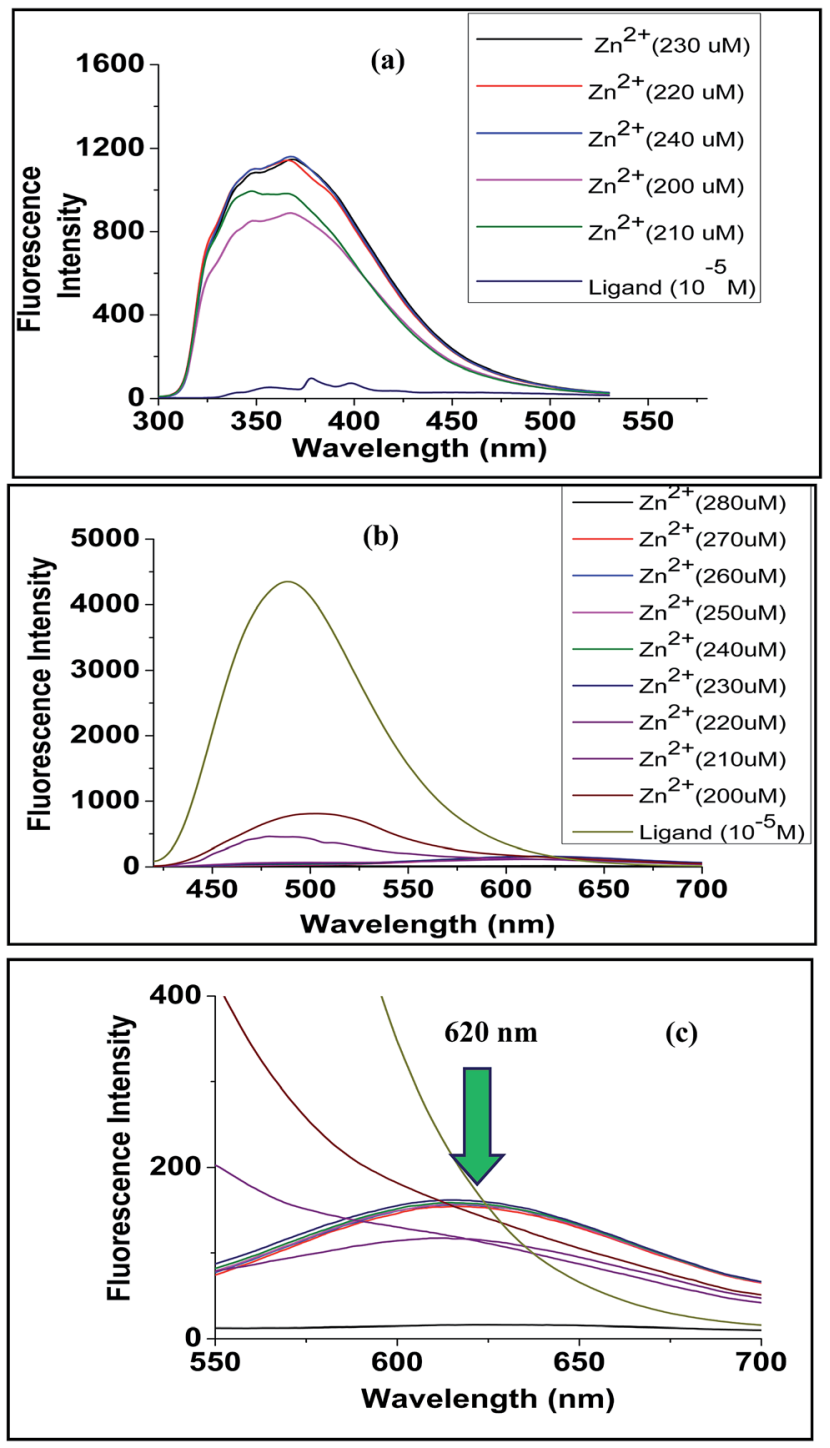

Fig. 15 Comparative fluorescence titration curve for (a) ligand L1 when titrated with $\mathrm{Zn}\left(\mathrm{ClO}_{4}\right)_{2}$ and (b) ligand $\mathrm{L} 2$ when titrated with $\mathrm{Zn}\left(\mathrm{ClO}_{4}\right)_{2}$ (c) expanded portion of (b).

and ligand showed more intense red fluorescence in high intensity (Fig. 17D).

When HaCaT cell were incubated with only ligand $\mathbf{L} 2$ very faint fluorescence expression was observed due to the zinc
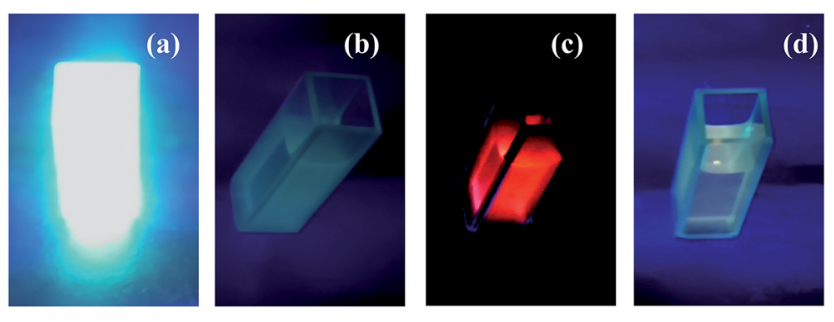

Fig. 16 Color change under UV radiation for different metal ions incubated with ligand L2: (a) ligand L2 (b) ligand $\mathrm{L} 2+\mathrm{Co}^{2+}$ (c) ligand L2 $+\mathrm{Zn}^{2+}$ and (d) ligand $\mathrm{L} 2+\mathrm{Ni}^{2+}$. 


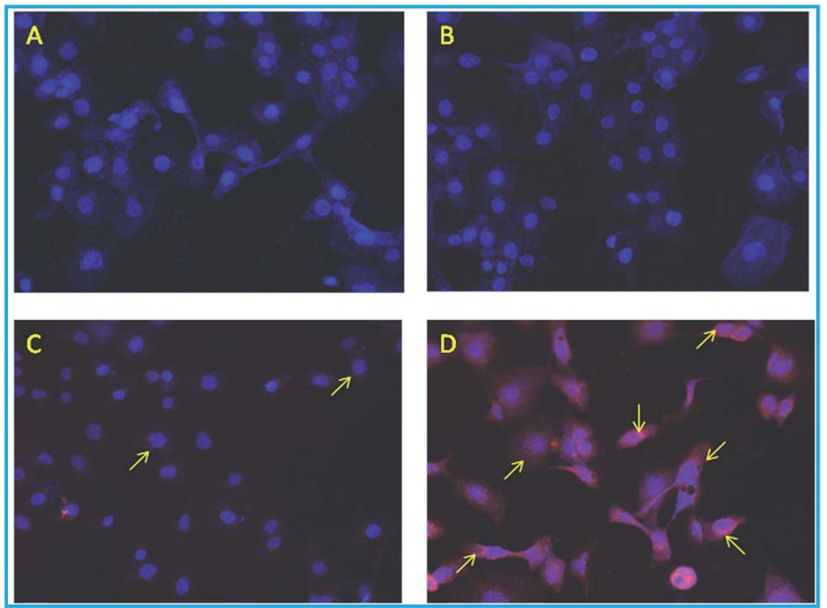

Fig. 17 Microphotographs (fluorescence microscopy-200× magnification) of cells treated as follows: (A) control (B) cell treated with $\mathrm{Zn}\left(\mathrm{ClO}_{4}\right)_{2}(\mathrm{C})$ cell treated with ligand $\mathrm{L} 2$ (D) cell treated with $\mathrm{Zn}\left(\mathrm{ClO}_{4}\right)_{2}$ + ligand L2 [red color indicates the fluorescence dye/ligand. Yellow arrow indicates the staining by the red fluorescence. Blue color indicates nucleus of the cell stained by DAPI (4',6-diamidino-2phenylindole)].

containing enzymes like metalloproteases, super oxide dismutase which reside in extracellular region $\left(\mathrm{SoD}_{1}\right.$ in cytoplasm, $\mathrm{SoD}_{2}$ in mitochondria), but the zinc treated cell showed strong red fluorescent signal after incubating it with ligand indicating a subcellular distribution of zinc ion. It suggests that zinc mapping is possible for the synthesized probe $\mathbf{L} 2$.

\section{Conclusion}

In conclusion, we have successfully synthesized pyrene-terpyridine ligands for detection of their metal ion complexation property. One of the ligand also acted as a new fluorescent probe highly selective for zinc ion in presence of other metal ions in the biologically relevant range. Zinc ion imaging was demonstrated using ligand $\mathbf{L} 2$ in HaCaT cell by observing interaction of $\mathrm{Zn}^{2+}$ with ligand $\mathbf{L 2}$. Ligand $\mathbf{L} 2$ showed strong red fluorescence for $\mathrm{Zn}^{2+}$ accumulated in the mitochondrial part of HaCaT cell.

\section{Acknowledgements}

We thank Professor Sanjib K. Patra, Department of Chemistry, IIT Kharagpur, for helpful discussion and suggestion. DST is acknowledged for an SERC grant (SB/S1/OC-94/2013) and for the JC Bose Fellowship to $\mathrm{AB}$ which supported this research. AM is grateful to IIT Kharagpur for a senior research fellowship and PB is grateful to CSIR, Government of India, for a research fellowship.

\section{References}

1 R. M. Roat-Malone, Bioinorganic Chemistry, Wiley, Hoboken, 2007.
2 (a) D. J. Sauke, D. E. Metzler and C. M. Metzler, Biochemistry: the chemical reactions of living cells, Harcourt/Academic Press, San Diego, 2nd edn, 2001; (b) A. Sigel, H. Sigel, and R. K. O. Sigel, Metal ions in life sciences, Wiley, Chichester, 2006.

3 S. J. Lippard and J. M. Berg, Principles of Bioinorganic Chemistry, University Science Books, Mill Valley, CA, 1994.

4 Binding, Transport and Storage of Metal Ions in Biological Cells, ed. W. Maret and A. Wedd, RSC publications, 2013.

5 B. R. Roberts, J. A. Tainer, E. D. Getzoff, D. A. Malencik, S. R. Anderson, V. C. Bomben, K. R. Meyers, P. A. Karplus and J. S. Beckman, J. Mol. Biol., 2007, 373, 877.

6 J. H. Laity, B. M. Lee and P. E. Wright, Curr. Opin. Struct. Biol., 2001, 11, 39.

7 (a) A. Basak, S. Mandal and S. S. Bag, Chem. Rev., 2003, 103, 4077; (b) B. Konig, H. Hollnagel, B. Ahrens and P. G. Jones, Angew. Chem., Int. Ed. Engl., 1995, 34, 2538; (c) B. P. Warner, S. P. Miller, R. D. Broee and S. L. Buchwald, Science, 1995, 269, 814; (d) A. Basak and K. R. Rudra, Tetrahedron Lett., 2000, 41, 7231; (e) D. S. Rawat and J. M. Zaleski, Chem. Commun., 2000, 2493.

8 (a) R. G. Bergman, Acc. Chem. Res., 1973, 6, 25; (b) R. R. Jones and R. G. Bergman, J. Am. Chem. Soc., 1972, 94, 660.

9 M. Jaishankar, T. Tseten, N. Anbalagan, B. B. Mathew and K. N. Beeregowda, Interdiscip. Toxicol., 2014, 7, 60.

10 (a) A. Manz, N. Graber and N. M. Widmer, Sens. Actuators, B, 1990, 1, 244; (b) D. J. Harrison, A. Manz, Z. Fan, H. Ludi and M. H. Widmer, Anal. Chem., 1992, 64, 1926; (c) S. Hiki, K. Mawatari, A. Hibara, M. Tokeshi and T. Kitamori, Anal. Chem., 2006, 78, 2859.

11 (a) Z. Dai and J. W. Canary, New J. Chem., 2007, 31, 1708; (b) J. R. Lakowicz, Principles of Fluorescence Spectroscopy, Springer, New York, 2006; (c) B. Valeur, Molecular Fluorescence Principles and Applications, Wiley-VCH, New York, 2002; (d) Y. Choi, Y. Park, T. Kang and L. P. Lee, Nat. Nanotechnol., 2009, 4, 742.

12 (a) J. J. Pitt, Clin. Biochem. Rev., 2009, 30, 19; (b) C. Lauridsen, S. W. Leonard, D. A. Griffin, D. C. Liebler, T. D. McClure and M. G. Traber, Anal. Biochem., 2001, 289, 89.

13 B. V. L'vov, J. Anal. Chem., 2005, 60, 382.

14 S. Ghosh, V. L. Prasanna, B. Sowjanya, P. Srivani, M. Alagaraja and D. Banji, Asian J. Pharm. Anal. Med. Chem., 2013, 3, 24.

15 D. Pröfrock and A. Prange, Appl. Spectrosc., 2012, 66, 843.

16 E. Witkowska, K. Szczepaniak and M. Biziuk, J. Radioanal. Nucl. Chem., 2005, 265, 141.

17 B. Beckhoff, B. Kanngießer, N. Langhoff, R. Wedell and H. Wolff, Handbook of Practical X-Ray Fluorescence Analysis, Springer, 2006.

18 G. J. Van Berkel and V. Kertesz, Rapid Commun. Mass Spectrom., 2013, 27, 1329.

19 (a) K. V. Kong, Z. Lam, W. K. O. Lau, W. K. Leong and M. Olivo, J. Am. Chem. Soc., 2013, 135, 18028; (b) S. K. Srivastava, R. Verma and B. D. Gupta, Sens. Actuators, B, 2011, 153, 194.

20 H. F. Li and J. M. Lin, Anal. Bioanal. Chem., 2009, 393, 555. 
21 R. B. Cole, Electrospray and MALDI Mass Spectrometry Fundamentals, Instrumentation, Practicalities, and Biological Applications, Wiley, Hoboken, 2010.

22 J. R. Cabrera-Pardo, D. I. Chai, S. Liu, M. Mrksich and S. A. Kozmin, Nat. Chem., 2013, 5, 423.

23 P. S. Addy, S. Basu Roy, S. M. Mandal and A. Basak, RSC Adv., $2014,4,23314$.

24 B. N. Ghosh, F. Topić, P. K. Sahoo, P. Mal, J. Linnera, E. Kalenius, H. M. Tuononen and K. Rissanen, Dalton Trans., 2015, 254.

25 A. Sil, A. Maity, D. Giri and S. K. Patra, Sens. Actuators, B, 2016, 226, 403.

26 W. Zecher and F. Kröhnke, Chem. Ber., 1961, 94, 690.

27 An alternate structure of $\mathrm{Zn}$ (II) complex could be thought of where the two ligands $\mathrm{H}_{2} \mathrm{O}$ and $\mathrm{OH}$ are replaced by $\mathrm{Cl}$. However the absence of isotopic peaks due to ${ }^{35} \mathrm{Cl}$ and ${ }^{37} \mathrm{Cl}$ made us to believe that it is indeed $\mathrm{OH}$ and $\mathrm{H}_{2} \mathrm{O}$ acting as the ligands. We have not seen the formation of dimers as was reported by Ghosh, et al. during incubation of ligand with the metal perchlorates which may be due to the bulky pyrene ring adding some steric compression in the dimeric complex. We thank the referee for drawing our attention to this aspect.

28 The spectrum showed in Fig. 12 is that of cobalt(II) complex with L2. The spectrum is not that bad even in presence of matrix as the polyaromatic absorbing the laser is already present. But if we use acetylacetone as the ligand, the spectrum of the cobalt complex in presence of matrix showed a small peak for $\mathrm{Co}(\text { acac })_{3}$ complex. This showed the advantage of using the polyaromatic label. The new spectrum of $\mathrm{Co}(\mathrm{acac})_{3}$ in presence of matrix is included in ESI. $\dagger$

29 (a) J. A. Kemlo and T. M. Shepherd, Chem. Phys. Lett., 1977, 47, 158; (b) A. W. Varnes, R. B. Dodson and E. L. Wehry, J. Am. Chem. Soc., 1972, 94, 946; (c) L. Fabbrizzi, M. Licchelli, P. Pallavicini, A. Perotti, A. Taglietti and D. Sacchi, Chem.Eur. J., 1996, 75.

30 A. Vogler and H. Kunkely Coord, Chem. Rev., 2000, 208, 321. 31 P. Boukamp, R. T. Breitkreutz, D. Hornung, J. Hornung, A. Markham and N. E. Fusenig, J. Cell Biol., 1988, 106, 761. 